\title{
HIV/AIDS: THE FIRST 25 YEARS - A VIEW FROM NAIROBI
}

\author{
P.H. REES
}

\begin{abstract}
SUMMARY
HIV infections are zoonoses occurring in communities that hunt chimpanzees (HIV 1) and sooty mangabeys (HIV 2) in the forests of equatorial and West Africa respectively. Most cross species transmission to man probably fizzles out, but the transmission of HIV 1 type M around 1930 eventually resulted in a pandemic that has spread around the world. HIV 2 types A and B have caused epidemics in West Africa. HIV infections are characterised by three phases (i) an initial, primary infective phase with rising viraemia, asymptomatic and silent, lasting for some 10 weeks, (ii) a long quiescent phase with the viraemia and illness mostly held in check by the immune response and lasting some 10 years in HIV 1 and 20 years or so in HIV 2 and (iii) a terminal third phase lasting some 10 months with rising viraemia, falling CD4 levels and multiple opportunistic infections recognised in a community by the onset of a florid AIDS epidemic. The silent primary epidemic reached Nairobi around 1980, with the florid secondary AIDS epidemic peaking here around 1992 and overwhelming the hospitals and other health services. The introduction of highly active antiretroviral therapy (HAART) has dramatically improved the prognosis for individual patients with AIDS, but it has been education and a changing attitude to condoms that has led to a progressive fall in incidence, so that the worst of the epidemic may now be over. Modifying the immunological response during the quiescent phase with the hope of prolonging this phase indefinitely may be the way forward for those who are already infected. Steroids have been shown to have a possible role here rather than anti-retroviral drugs (ARVs) which are not curative and prone to the development of drug resistance. Limited personal experience suggests that steroids may also have a role in salvaging critically ill AIDS patients, who need to be treated as emergencies. With an educated public and attention to alternative routes of infection such as blood transfusion, the epidemic should be increasingly contained during the next 25 years, and may even fizzle out.
\end{abstract}

\section{INTRODUCTION}

Sometime in 1980, perhaps a year or two earlier, the first HIV patient must have been seen in Nairobi. By 1981, 4\% of Nairobi's female sex workers were unknowingly carrying HIV (1). Quite fortuitously blood had been taken in 1981 as part of research into chancroid. When the stored blood was tested four years later, five out of 116 samples were HIV positive as were 174 of the 286 samples $(61 \%)$ taken from a similar prostitute population in 1985. The research team had been observing a silent epidemic of HIV with nothing to note but the changing serology, from $4 \%$ positive to $61 \%$ positive. By the time AIDS was announced to the world on $5^{\text {th }}$ June 1981 from Los Angeles (2), an epidemic was already under way in Nairobi.

\section{EARLY HISTORY}

In Los Angeles, five gay men had developed pneumocystis carinii pneumonia (PCP). Two were already dead. A report from New York and California rapidly followed describing Kaposi's sarcoma in 26 gay men, 10 further gay men with PCP and four gay men with severe perianal herpes simplex 
infections, three of whom had already died (3). Oral and oesophageal candidiasis, CMV infections, cryptococcal meningitis and cerebral toxoplasmosis were also reported. Low T-lymphocyte counts were noted. The syndrome was given the acronym GRID (gay related immune deficiency). Reports of the syndrome in intravenous drug users, Haitians and haemophiliacs followed. GRID was renamed AIDS, but the stigma of AIDS had been set as a disease of gay men somehow related to anal intercourse.

In 1983, Obel, et al (4) from the University of Nairobi's Department of Medicine and the Kenyatta National Hospital made the first published diagnosis in Africa. The patient, a heterosexual Ugandan journalist, had probably acquired the illness during travels to the strife ridden Uganda/Rwanda/ Tanzania border area sometime from 1979 onwards (Obel, personal communication, 2007).

Meanwhile AIDS was being increasingly seen in France and Belgium. Many patients had associations with equatorial Africa, especially the Congo. In late 1983, a visiting team diagnosed AIDS in patients at the Mama Yemo Hospital in Kinshasa (5).

\section{DISCOVERY OF THE VIRUS}

Early in 1983, the causative retrovirus was identified in Paris from the blood of a male Caucasian homosexual with lymphadenopathy associated virus (LAV) (6). A year later, two papers followed in quick succession from the USA. The first (7) from the Gallo group at the National Cancer Institute who had identified the same virus in AIDS patients, and confusingly renamed it HTLV III (Dr Gallo had previously identified HTLV I and II, oncogenic retroviruses). The second (8), from San Francisco, established that the lentivirus the French had discovered (LAV) was also responsible for AIDS (and confusingly called it ARV, AIDS related virus).

There followed some squabbling over the primacy of discovery of the virus. Extraordinarily the dispute was settled in 1987 by a pronouncement from Presidents Chirac and Reagan (9) giving joint primacy to Paris and, questionably, to Gallo, but omitting the definitive role of the San Francisco group. Not surprisingly, the primacy dispute lingered on (10). By this stage the earlier names, LAV, ARV and HTLV Ill had been replaced by HIV (Human Immunodeficiency Virus), a second HIV
(HIV 2) had been found in West Africa (11) and an immunodeficiency virus had been found in a non human primate, the simian immunodeficiency virus of the African green monkey, SIV agm (12).

Further confusion followed the introduction of the first serological tests in 1984. Some of these were oversensitive and non-specific so that populations, for example in West Nile in Uganda and Turkana in Kenya were mistakenly labelled as having endemic HIV. False positive results with malarial and other antibodies were a frequent problem with early HIV tests (9).

\section{EARLY EAST AFRICAN OBSERVATIONS}

Given the stigma of a disease of male homosexuals, the squabbling over who had first identified the causative virus when quite clearly the French had, and the false labelling of African populations as endemic for HIV based on faulty serology, it is not surprising that the whole AIDS business was greeted by some, especially in Africa with a mixture of disbelief and hostility. De Cock, who had recently left the University of Nairobi's Department of Medicine and the Kenyatta National Hospital, wrote his perceptive hypothesis (13) on the probable African origin of AIDS in 1983 from Los Angeles, the then world centre of AIDS. This hypothesis was not well received (De Cock, Personal communication, 2007) nor was Obel's case report. The medical authorities who might have been grateful for the timely warning that Kenya was on the edge of an epidemic, instead chided Obel for publishing an alarmist report, and asked him to be quiet about the subject. Carswell in Uganda was having similar problems with the authorities in drawing attention to the epidemic of SLIM disease in the lake side border area with Tanzania. Some of the first reliable serology confirmed an association of SLIM with HIV (14), and also established that HIV in Africa was heterosexually transmitted, a proposition met with disbelief by many in America. Carswell continued to draw attention to the evolving epidemic but eventually left Uganda in 1987 after two of his staff were bludgeoned to death in uncertain circumstances (Carswell, Personal communication, 2007). But the world's perception of the epidemic might have developed differently if more attention had been paid to Idi Amin. 
In 1976, the then president of Uganda announced that his troops had reported to him a new, untreatable and fatal venereal disease that they called "good hope", as hope was all there was to confront it (Carswell, Personal communication, 2007). And again in 1979 towards the end of the Tanzania/ Uganda war, Amin claimed that his soldiers reported a strange wasting disease among the Tanzanians across the border (9). This was probably a reference to the SLIM presentation of AIDS, though it is not clear whether Idi Amin was aware that this wasting disease might be related to the disease called 'good hope' which he had referred to in 1976.

That Idi Amin should be making pronouncements about venereal and wasting diseases based on information from his troops was not surprising. He was close to his soldiers. On two occasions, Carswell, as duty surgeon, recalls meeting Amin when the President had personally driven some of his wounded soldiers to casualty at the New Mulago Hospital in his own vehicle. But substantiating Idi Amin's statements has been difficult (Carswell, Personal communication, 2007). In September 1976, on the front page of the Argus (15), Uganda's leading newspaper at the time, he is quoted as commenting on the "increase of venereal disease cases in some countries" and appealing "to every Ugandan who catches VD to go to hospital for immediate treatment". A year later, The Venereal Diseases Decree, 1977 was signed into law and introduced by Idi Amin in his capacity as Life President as well as Minister of Health (16). Amongst other things this decree allowed for the detention of sufferers of a venereal disease until they were no longer a risk to others, for the rounding up of those who might harbour venereal diseases for treatment and training and that those taken to court and convicted, "must not be given useless light sentences". Later, again in the Argus (17), Idi Amin decided that all types of venereal diseases should be referred to as "good hope" to avoid embarrassment. "All the sufferer has to do is tell the doctor 'good hope'.... and he will get treatment accordingly". To have issued something as extraordinary as a Venereal Diseases Decree suggests that Idi Amin was alarmed. This alarm might well have been triggered by reports from his soldiers about developments in the neighbouring countries, developments that were confirmed when the work of retrospectively surveying the spread of AIDS prior to its 'discovery' in 1981 was undertaken.

\section{VIROLOGY AND ORIGINS}

Retrospective surveys, largely conducted to identify the source and history of HIV / AIDS, are described in detail and are well referenced in two books, The River by Edward Hooper (9) and The African AIDS Epidemic by John Iliffe (18). Retrospective surveys include testing of stored blood samples for HIV antibodies, using polymerase chain reaction (PCR) technology to find the virus itself in stored blood and postmortem specimens, and clinical searches and interviews for the earliest records of probable AIDS patients. These surveys pointed to equatorial Africa, between Cameroon and the Congo, as the probable area of origin. The oldest positive HIV serology (19) was a sample taken from a man in the area of Kinshasa, (then Leopoldville) in 1959. The earliest epidemic of probable AIDS was recalled by Dr Kapita Bila and other doctors based at Kinshasa's main hospital, the Mama Yemo. Around 1975, they noted a dramatic increase of an AIDS like illness characterised by Kaposi's sarcoma, diarrhoea, ulceration of the mouth and cryptococcal meningitis (18).

Important in interpreting these retrospective surveys are the unstable nature of immunodeficiency viruses, the unique natural history of the HIV / AIDS illness, the finding of immunodeficiency viruses in primates, and the discovery of HIV 2 in West Africa.

Immunodeficiency viruses are RNA retroviruses. They use the enzyme reverse transcriptase to convert their RNA to host cell DNA and then back again to the RNA of a newly formed virus. Mutations crop up in this double transcription process at a roughly predictable rate. Recombination is a further source of variability. In a host infected with two different types of HIV, a fragment of one type may combine with a fragment of the other type to give a recombinant virus. Though complex, this variability allows the ancestry of a particular virus to be traced (20). Because of the roughly predictable rate of mutation, a time frame can be given. The year a virus may have separated from a common ancestor or have crossed the species barrier may be estimated.

The natural history of an HIV / AIDS illness has three stages. The first stage lasts for roughly ten weeks. From initial infection, unchecked viraemia develops to levels of one million viruses per $\mathrm{ml}$ or more with corresponding infectiousness and 
the potential for an explosive yet silent primary epidemic. This stage ends with an immune response often marked by a seroconverting illness. The second or latent stage, characterised by the continuing immune response with viraemia falling to low or undetectable levels, lasts for ten years or so and carries relatively little risk of transmitting infection. The final stage, AIDS, begins with viraemia increasing and the CD4 T-lymphocyte count falling. Multiple opportunistic infections occur. Without treatment death occurs in ten months or so.

The finding of a retrovirus similar to HIV in African green monkeys (SIV agm) suggested the possibility of a primate origin for HIV. The discovery and investigation of HIV 2 and its close relationship to the SIV of the sooty mangabey (SIV $\mathrm{sm})$, confirmed this suspicion.

\section{LESSONS FROM HIV 2 AND OTHER VIRUSES}

HIV 2, discovered more or less by chance in 1985 during a serological survey in Senegal, has been largely confined to the West African coast from Senegal, on the western tip of Africa to the Ivory Coast, a stretch of 1000 miles between the Casamance and Sassandra rivers. These rivers define the tropical rain forest habitat of the sooty mangabey, Cercocebus torquatus atys, a slender monkey that characteristically carries its long tail vertically upwards and arched forwards over its body. Big rivers, like the Casamance and Sassandra, are frequent habitat boundaries for primate species in Africa because of the reluctance or inability of primates to swim. HIV 2 is more closely related to SIV sm, than it is to HIV 1, and subtypes of HIV 2 in turn are more closely related to subtypes of SIV sm than they are to each other (21). Several subtypes of HIV 2 have been identified, suggesting that SIV sm has been successfully transmitted to man on at least eight occasions. Most of these have fizzled out, but HIV 2 type B, estimated to have been transmitted from a sooty mangabey to man around 1945, gave rise to an epidemic in the Ivory Coast. HIV 2 type A probably passed from monkey to man a little earlier, and reaching Portuguese Guinea, now Guinea Bissau, in the 1950's, found an environment suitable for a silent primary HIV epidemic. Many Portuguese soldiers had been posted far from home to combat the independence war. This primary epidemic passed unnoticed. With HIV 2's long latent stage, 20 years or more, the earliest retrospective report (22) of HIV 2 AIDS was in a Portuguese restaurateur, who had lived in Guinea Bissau from 1955 to 1965 and developed symptoms of AIDS in 1975. There has been some spread of HIV 2 outside West Africa, especially to countries with Portuguese connections such as Angola, Mozambique and Goa, but it seems that HIV 2 may be declining. In the 1990's the peak prevalence in Guinea Bissau was amongst men in their 60's and women in their 50's, reflecting infections acquired 20 to 30 years previously.

That HIV 2 originated in a primate host can hardly be much of a surprise. Zoonoses are common, especially where contact with animals is intense, as in the poultry industry in the far east and bird flu. Close contact with primates is more restricted, but as well as being hunted and butchered to be served in restaurants and homes as meat, sooty mangabeys are kept as pets. Transmission in such circumstances has been quantified by a survey of 1099 hunters and others having close contact with primates and primate meat in Cameroon. Eleven of them had evidence of infection with the simian foamy virus (SFV), a common primate retrovirus, harmless to humans (23).

Transmission of primate viruses to laboratory and zoo workers has been a recognised hazard for many years. In 1934, Sabin described a fatal viral ascending myelitis from a rhesus monkey bite during experimental work on poliomyelitis (24). Much of polio vaccine development depended on altering and attenuating polio virus in monkey kidney tissue culture. Numerous naturally occurring monkey viruses were identified during this process. The fortieth, SV 40, was inadvertently given to millions of children in the United States in oral and parenteral polio vaccines before its presence was realised. Fortunately, although it is an oncogenic virus, this massive administration does not seem to have caused any problems (25). The danger of using monkeys for tissue culture and the preparation of vaccines was emphasised when apparently healthy vervets, African green monkeys, Cercopithecus aethiops, were flown from Uganda to a vaccine production unit in Marburg, Germany. Thirty one laboratory workers and their contacts developed a severe illness with seven fatalities.

Transmission of Marburg virus occurred in the Nairobi Hospital in 1980 (26). A 56 year old 
Frenchman living close to the Uganda border on the lower slopes of Mount Elgon and not far from the area in Uganda from where the African green monkeys incriminated in the original Marburg incident had been collected, developed a haemorrhagic febrile illness with hepatitis. The contagious nature of the illness was not suspected. He was flown to the Nairobi Hospital but died six hours after admission. The physician who attempted resuscitation became ill nine days later with Marburg virus disease, eventually making a complete recovery. The source of the initial illness could not be identified, though it was assumed to be a zoonosis, just as the other prominent African haemorrhagic fevers, Ebola and Lassa are assumed to be zoonoses.

SIV's have been found in 26 species of primate (21). They are generally harmless to their preferred hosts. All are in monkeys apart from SIV cpz found in the chimpanzee subspecies, Pan troglodytes troglodytes, though even SIV cpz has monkey origins. It is a recombinant virus (27), with half of its genome coming from the SIV of the red capped mangabey, Cercocebus torquatus torquatus and the other half from the SIV of the greater spot nosed monkey, Cercopithecus nictitans. These monkeys often move together in mixed troops. They share the same habitat range as Pan troglodytes, 1000 miles east of HIV 2 terrain, between the Cross river in Nigeria and the mouth of the Congo as it empties into the southern Atlantic. Their young are sometimes attacked and eaten by chimpanzees. The resultant recombinant virus, SIV cpz, is the most similar SIV to HIV 1.

HIV 1 is complex (20). There are three main types, $\mathrm{M}, \mathrm{N}$ and $\mathrm{O}$, each more closely related to types of SIV cpz than each other. N, the least important, is confined to Cameroon. O has caused a minor epidemic. Mis responsible for the global pandemic. Precisely what happened may never be established. Based on mutation clock calculations HIV 1 type M crossed from chimpanzee to man around 1931. There followed an explosive mutation of HIV $1 \mathrm{M}$ in human hosts with the development of 10 subtypes $\mathrm{A}$, $\mathrm{B}, \mathrm{C}, \mathrm{D}, \mathrm{F}_{1^{\prime}} \mathrm{F}_{2}, \mathrm{G}, \mathrm{H}, \mathrm{J}$ and $\mathrm{K}$ over the next 30 years. In the 1950's and 1960's, equatorial Africa with Kinshasa at its hub became internationalised. Traffic to and from many parts of the world multiplied, continuing old links with Europe and developing new links as with the influx of thousands of Haitian technocrats to help develop the newly independent
Congo. These links and the evolving transport routes by air and road have been important in distributing HIV 1 to Africa and the rest of the world.

Retrospective studies suggest that HIV $1 \mathrm{M}$ subtype B was transported to Haiti around 1966 (28). Around 1969, quite possibly by a single carrier, subtype B was introduced from Haiti to the USA and ignited the gay epidemic, though this did not become apparent until the first patients with PCP and Kaposi's sarcoma presented some 10 years later. $B$ is now the main subtype found in the USA and also in Europe.

Given the coincidence of the more or less synchronous development of HIV 1 and HIV 2, there has been speculation on how two primate viruses SIV sm and SIV cpz should at the same time make the transfer from primate to man and cause epidemics. The main theme of Hooper's book, The River, is the possible role of oral polio vaccine in creating the epidemic (9). In the 1950's there was much worldwide research on oral polio vaccine. Some of this research was based at Stanleyville (now Kisangani) on the middle Congo, 500 miles east and upstream of the fork giving rise to the Oubangui, the northern tributary of the Congo. The Oubangui is the eastern boundary of the habitat of Pan troglodytes. The company involved kept a chimpanzee colony for research purposes. Chimpanzees were captured from the north bank of the middle Congo, the habitat of the long haired Pan troglodytes schweinfurthi, and from the south bank, the habitat of the pygmy chimpanzee Pan paniscus. Neither species are establised hosts of SIV cpz, and it is unlikely that chimpanzee kidneys were used in vaccine production. Although, given the experience with SV40, the oral polio theory is plausible, the data simply does not fit, though this does not detract from the value of Hooper's book as a history of the AIDS epidemic.

Other theories proposed a role for vaccination programmes and poor needle and syringe hygiene. In putting forward such theories, much weight has been given to the very low infectivity of HIV 1 (29, $30)$, transmission occurring as rarely as only once in a thousand exposures between otherwise healthy discordant couples, and the even lower infectivity of HIV 2. This level of infectivity would be unlikely to get an epidemic going, but is misleading as it refers to the latent second stage of HIV with low or undetectable viral loads. The primary stage of HIV, with viral loads hundreds or thousands of times 
greater than in the latent stage, can be predicted to be infinitely more infectious. This, perhaps coupled with an increased risk of transmission on traumatic anal intercourse, seems to have been enough for a single traveller from Haiti to fuel the epidemic in the gay population of the three US cities, Los Angeles, San Fransisco and New York. No doubt it was not so explosive in Kinshasa and Guinea Bissau and elsewhere in Africa, but it is easy to see how one individual with a high viral load might infect ten others during the few weeks prior to the seroconverting illness. The ten new infections might each infect ten more and so on, so that in a period of a few months a city might be hosting a silent epidemic of 10,000 or more.

\section{SPREAD IN EAST AFRICA}

Subtypes A and D are responsible for the Nairobi epidemic. Their spread $(9,18)$ seems to have been across the Congo through Rwanda and Burundi to the lakeshore areas of north west Tanzania and south western Uganda, areas familiar to Idi Amin's soldiers and where the stories of "good hope" may well have arisen. The spread through Uganda was facilitated by the first border war of 1979 with Amin's defeat by the Tanzania army. Further spread followed the second war when Museveni's forces overcame the Obote Government in 1986, but by this time the silent primary epidemic was already under way in Nairobi.

In the latter half of 1980, I started seeing patients at the private Nairobi Hospital as well as continuing to work at the Kenyatta National Hospital. Professors Kungu and Gatei (31) were putting the final touches to their study on Kaposi's sarcoma in Kenya, a few months before the gay epidemic made Kaposi's a marker for AIDS. As in other parts of Africa, Kaposi's was relatively common, one of the reasons De Cock proposed (13) Africa as the origin of HIV, postulating a viral aetiology for Kaposi's, now clearly associated with HHV8 (human herpes virus 8). A year or two later, Professor Bayley visited the office to see whether the event she was witnessing in Lusaka (32), a dramatic increase in an aggressive form of Kaposi's, was also occurring in Nairobi. There was no apparent increase at that time, but at the Nairobi Hospital, I had been surprised to find several patients with unusual febrile illnesses, mainly expatriates who had been living in other parts of eastern Africa. Generally, the illnesses resolved within a week or so without any specific treatment. One was especially severe with fever, myalgia, and peripheral neuropathy, dying after a week or so in intensive care. Another with fever and lymphadenopathy happened to be travelling to California. There she was seen by Dr. De Cock. Apart from reactive lymphadenopathy, no specific diagnosis was made. With hindsight these pyrexias of unknown origins (PUOs) may well have been sero-converting illnesses or so-called persistent generalised lymphadenopathy. A severe sero-converting illness in a Nairobi resident was seen at the Nairobi Hospital in 1984 (33), the first report of a sero converting illness from Africa.

\section{TREATMENT}

Increasingly AIDS patients were seen swamping the government hospital as well as the private sector, with the AIDS epidemic peaking in the 1990's. Treatment was largely aimed at opportunistic infections.

AZT had been developed in the 1960's and in 1986 was at last found to have a use as a reverse transcriptase inhibitor; but as monotherapy it was disappointing, as was Kemron, which also had theoretical anti viral potential. Many treatments were experimented with in desperation. In my own experience, for example, steroids were the most useful, often leading to objective and subjective benefit both in specific HIV problems such as neuropathies, and in alleviating symptoms in the terminal phase. Given the immunosuppressive properties of steroids, there has been an understandable reluctance to use them in an illness characterised by immunodeficiency. If steroids are given to a healthy individual, the lymphocyte count and the CD4 count fall, but if steroids are given during the quiescent phase of HIV, the CD4 count increases, even in the absence of specific anti viral therapy (34).

Prednisolone from $5 \mathrm{mg}$ to $35 \mathrm{mg}$ daily may be given, possibly for many years, increasing the CD4 count with no increased viraemia and no increased risk of immunodeficient illness relative to controls (35). Massive doses, 200mg prednisolone, are limited by steroid side effects (36). The beneficial effect of prednisolone suggests that hyperactivity of the immune system and its subsequent exhaustion may be important, rather than direct damage of the immune system. 
The introduction of HAART, highly active antiretroviral therapy, in 1996 has changed the prognosis of AIDS. The arrival of affordable triple therapy in Nairobi was dramatic. Overnight from a situation where death was inevitable, it became possible to salvage even the most desperately ill patients. Controversies remain how early to start treatment. Drug intolerance and the development of viral resistance are problems that negate early treatment. It may be best to hold off treatment as long as possible at least until the CD4 count is down to 200 / $\mathrm{ml}$, assuming the patient remains well.

If patients are first seen when critically ill with very low CD4 counts and multiple opportunistic infections, treatment should be started as an emergency. Because of fears of precipitating an immune reconstitution syndrome with a dramatic inflammatory reaction to opportunistic infections, initiation of HAART is sometimes delayed whilst opportunistic infections are investigated and treated. This may well allow a bad situation to deteriorate further. In any case it is often impracticable, if not impossible, to fully investigate opportunistic infections and their treatment may be unaffordable or unavailable. I have found a combination of steroids with HAART generally results in a dramatic improvement within a day or two of starting treatment. Prednisolone in moderate dose, $20 \mathrm{mg}$ two to three times daily, tapering down to $20 \mathrm{mg}$ daily, seems to be adequate.

\section{PROSPECTS AND PRIORITIES}

Although the advent of HAART has had a profound effect on the individual patient, much more importantly, it seems the worst is over for Kenya (37). The incidence, the rate of new infections, peaked around 1992 and overall the situation continues to improve. Education may be largely responsible for this good result. There has been much publicity so that the mode of transmission is widely known and the "ABC, abstinence, be faithful or condoms," widely understood. Any public debate is useful. If condoms are proposed by one sector, and disapproved by another, it may not matter who wins the public debate. People will understand the importance of condoms, and make their own informed choice, though a clear lead is helpful as when the Kenyan Minister of Health was photographed demonstrating the correct application of a condom. President Museveni realised the importance of education early (18). His view was "To not be open about AIDS is just ignorant. This is an epidemic. You can only stop it by talking about it - loudly so that everybody is aware and scared, and they stop the type of behaviour that encourages the spread of the disease".

Given the declining incidence of HIV in Kenya, consideration should now be given as to how to push the incidence even lower and hopefully to extinction. Perhaps surprisingly, HAART will not have been responsible for the improving epidemic situation, though it has been so successful in prolonging the lives of those with AIDS, for 10 and hopefully for 20 years or more with the restoration of an active life, but $20 \%$ of new infections in England are now due to drug resistant strains of $\mathrm{HIV}$, and the probability is that most of these new infections have come directly or indirectly from persons already on HAART. The same course of events may not follow in Kenya, but the possibility provides a strong argument for giving "ABC and condoms," the emphasis over treatment with HAART. If drug resistant strains develop in Kenya, treatment will become less sure and more expensive. Kenyan voluntary counselling and test centres (VCT's) are well aware of the danger, and make available free condoms for all those on treatment.

For the moment, first priority for drug use might be given to blocking mother-to-infant transfer. With a more aggressive approach than is current, it may be possible to achieve almost $100 \%$ protection for the infant.

Blood transfusion, with the almost certainty of transmission of HIV, is an obvious concern. When the AIDS situation was explored in Kinshasa in 1984 (18), it was noted that the Mama Yemo gave some 80 transfusions a day, and at least 5\% of these were HIV positive, so that the hospital was creating four new infections a day. To reduce, but not absolutely eliminate, the risks of transmitting HIV and other diseases by blood transfusion, costs the UK some $£ 500$ million annually (38). Much of this expenditure may be wasted as health economists are now beginning to realise that a great deal of the transfusion of blood and blood products has little if any evidence to justify it. Jehovah's witnesses with their prohibition of the use of blood, may occasionally lose a member and surgeons are sometimes severely challenged by this restriction, but there can be little doubt that if the prohibition 
had been applied in Kenya, or indeed throughout Africa over the last 25 years, there would be a large credit in terms of morbidity and mortality.

The exceptionalisation of HIV, the premise that the practice and ethics of HIV are different to the rest of medicine, has had several impacts, including the allocation of huge sums of money specifically for HIV and the development of pretest counselling. A 2006 conference on HIV / AIDS attended by 30,000 people, cost an estimated minimum of $£ 30$ million, (Kshs 4 billion). An international health consultant observer concluded (39) it was "still unclear if the huge resources poured into HIV / AIDS are effectively targeted, where exactly the successes and failures occur, and who is accountable". Surely enough is now known to apply the huge funds to the roots of the problem, to education and condoms, and to use whatever is left over, for treatment. The expensive search for a vaccine against a rapidly mutating and recombining virus, which has bombarded the immune system for 10 to 20 years without producing anything but transient immunity, is optimistic if not entirely hopeless.

Patients see their doctors to find out if there is anything amiss, or if they are already ill, what is wrong? In this process, counselling may be appropriate at any stage, but is generally left to the discretion of the doctor, the needs of the patient and doctor/patient interaction.

Obligatory pretest HIV counselling has certainly led to delays, or worse the omission of testing. Often the doctor is uncomfortable and reluctant to stress the patient with pre-test counselling. The result is that men, especially, leave the office/hospital to infect their hitherto uninfected partners, and illnesses are not cut short by precise treatment but continue for weeks or months with ineffective treatment and progressively falling CD4 counts. Finally when the patient is too ill to discuss the test, it is done anyway and without any anxiety or fuss.

\section{THE FUTURE}

What is the best way forward? Having been exceptionalised, how would the public react to deexceptionalisation of HIV? Let ministries determine how the vast sums of money should be spent, whether on education, condoms or treatment, or even on a non-HIV health priority which seems more pressing than HIV. Let doctors talk to their patients and determine whether they are ill or not, and what needs to be done. That is the time for counselling.

Thirty five years ago at a conference on venereal disease at the Kenyatta National Hospital, I had the temerity to suggest that if condoms were adopted there would be no need for the conference. This was not well received, the audience's response epitomised by the public health specialists who commented "That would be like taking a shower under an umbrella". Whilst appreciating this older culture, force of circumstances and education now seem to have modified the culture.

Ministries of Health officials are clear on their priorities. Members of the public too, now so much better medically educated, will also have made up their minds. Would they agree that education or drugs are the first priority? Would they want HIV / AIDS funds spent on conferences or condoms?

\section{ACKNOWLEDGEMENTS}

I am most grateful for invaluable advice, discussions and contributions to Dr Wilson Carswell, Dr Kevin De Cock, Dr Shem Musoke and Professor Arthur Obel and to Ms Florence Oyuu for secretarial services and for travelling to Entebbe and Kampala to research the references to Idi Amin Dada.

\section{REFERENCES}

1. Piot, P., Plummer, F.A., Rey, M.A., et al. Retrospective seroepidemiology of AIDS virus infection in Nairobi populations. J. Inf. Dis. 1987; 155: 1108-1112.

2. Gottlieb, M.S., Schanker, H.M., Fan, P.T., et al. Pneumocystis pneumonia - Los Angeles. MMWR. 1981; 30: 250-252.

3. Friedman-Kien, A., Laubenstein, L., Marmor, M., et al. Kaposi's sarcoma and pneumocystis pneumonia among homosexual men - New York City and California. MMWR. 1981; 30: 305 - 308.

4. Obel, A.O.K., Sharif, S.K., McLigeyo, S.O., et al. Acquired immunodeficiency syndrome in an African. East Afr. Med. J. 1984; 61: 724-726.

5. Piot, P., Taelman, H., Minlange, K.B., et al. Acquired immunodeficiency syndrome in a heterosexual population in Zaire. Lancet. 1984; ii: 65-69.

6. Barré-Sinoussi, F., Chermann, J.C., Rey, F., et al. Isolation of a T-lymphotropic retrovirus from a patient at risk for Acquired Immune Deficiency Syndrome (AIDS). Science. 1983; 220: 868-871. 
7. Gallo, R.C., Salahuddin, S.Z., Popovic, M., et al. Frequent detection and isolation of cytopathic retroviruses (HTLV-111) from patients with AIDS and at risk for AIDS. Science. 1984; 224: 500-503.

8. Levy, J.A., Hoffman, A.D., Kramer, S.M., et al. Isolation of lymphocytopathic retroviruses from San Francisco patients with AIDS. Science. 1984; 225: 840-842.

9. Hooper, E. The River. The Penguin Press, 1999.

10. Greenberg, D.S. Resounding echoes of Gallo case. Lancet. 1995; 345: 639.

11. Barin, F., Denis, F., Allan, J.S., et al. Serological evidence for virus related to simian T-lymphotropic retrovirus III in residents of West Africa. Lancet. 1985; ii: $1387-1389$.

12. Kanki, P.J., Alroy, J. and Essex, M. Isolation of Tlymphotropic retrovirus related to HTLV - 11l/LAV from wild-caught African green monkeys. Science. 1985; 230: 951-954.

13. De Cock, K.M. AIDS: An old disease from Africa? Brit. Med. J. 1984; 289: 306-308.

14. Serwadda, D., Sewankambo, N.K., Carswell, J.W., et al. Slim disease: A new disease in Uganda and its association with HTLV-III infection. Lancet. 1985; ii: 849-852.

15. Idi Amin Dada. Increase of venereal disease. We must have healthy families if we are to build a healthy future. Uganda Argus. 1976.

16. Idi Amin Dada. Venereal disease decree. Uganda Government Press, 1977.

17. Idi Amin Dada. From now on name it good hope. Uganda Argus. 1978.

18. Iliffe, John. The African AIDS epidemic: A history. James Currey, Oxford, 2006.

19. Nahmias, A.J., Weiss, J., Yao, et al. Evidence for human infection with an HTLV III / LAV-like virus in Central Africa, 1959. Lancet. 1986; i: 1279-1280.

20. McCutchan, F.E. Understanding the genetic diversity of HIV-1. AIDS. 2000; 14: (Suppl 3) 531-544.

21. Hahn, B.H., Shaw, G.M., De Cock, K.M., et al. AIDS as a Zoonosis. Science. 2000; 287: 607-614.

22. Brycseson, A., Tomkins, A., Ridley, D., et al. HIV 2 associated AIDS in the 1970's. Lancet. 1988; 2: 221.

23. Wolfe, N.D., Switzer, W.M., Carr, J.K., et al. Naturally acquired simian retrovirus infections in Central African hunters. Lancet. 2004; 363: 932-937.

24. Sabin, A.B. and Wright, A.M. Acute ascending myelitis following a monkey bite, with the isolation of a virus capable of reproducing the disease. J. Experimental Med. 1933; 59: 115-136.
25. Shah, K. and Nathanson, N. Human exposure to SV40: Review and comment. Amer. J. Epidemiol. 1976; 103: 1-11.

26. Smith, H.D., Johnson, B.K., lsaacson M., et al. Marburgvirus in Kenya. Lancet. 1982; i: 816-820.

27. Bailes, E., Gao, F., Bibollet-Ruche, F., et al. Hybrid origin of SIV in chimpanzees. Science. 2003; 300: 1713.

28. Gilbert, M.T.P., Rambaut, A., Wlasiuk, G., et al. The emergence of HIV / AIDS in the Americas and beyond. Proc. Natl. Acad. Sci. USA. 2007; 104: 18566-18570.

29. Gray, R.H., Wawer, M.J., Brookmeyer, R., et al. Probability of HIV-1 transmission per coital act in monogamous, heterosexual, HIV-1 discordant couples in Rakai, Uganda. Lancet. 2001; 357: 1149-1153.

30. Cameron, D.W., D'Costa, L.J., Maitha, G.M., et al. Female to male transmission of human immunodeficiency virus type 1: Risk factors for serocoversion in men. Lancet. 1989; 2: 403-407.

31. Kungu, A. and Gatei, D.G. Kaposi's sarcoma in Kenya. Antibiotic Chemother. 1981: 26: 38-55.

32. Downing, R.G., Eglin, R.P. and Bayley, A.C. African Kaposi's sarcoma and AIDS. Lancet. 1984; i: 478-480.

33. Biggar, R.J., Johnson, B.K., Musoke, S.S., et al. Severe illness associated with appearance of antibody to Human Immunodeficiency Virus in an African. Brit. Med. J. 1986; 293: 1210-1211.

34. Ulmer, A., Muller, M., Bertisch-Mollenhoff, B., et al. Low dose prednisolone has a CD4 - stabilizing effect in pre-treated HIV patients during structured therapy interruptions (STI). Eur. J. Med. Res. 2005; 10: 227-232.

35. Andrieu, J.M. and Lu, W. Long-term clinical, immunogologic and virologic impact of glucocorticoids on the chronic phase of HIV infection. BMC. Med. 2004; 2: 17.

36. Mayanja-Kizza, H., Jones-Lopez, E., Okwera, A., et al. Immunoadjuvant prednisolone therapy for HIVassociated tuberculosis: A phase 2 clinical trial in Uganda. J. Infect. Dis. 2005; 191: 856-865.

37. Shelton, J.D., Halperin, D.T. and Wilson, D. Has global HIV incidence peaked? Lancet. 2006; 367: 1120.

38. McClelland, D.B.L. and Contreras, M. Effectiveness and safety of blood transfusion. Have we lost the plot? J. R. Coll. Phys. Edinb. 2005; 35: 2-4.

39. Logie, D.E. Toronto 2006: Time to deliver on HIV/ AIDS. J. R. Coll. Phys. Edinb. 2006; 36: 290-292. 